\title{
Axial Compressive Behavior of Rope Fiber Reinforced Polymer Composite Concrete
}

\author{
SUNITI Suparp* \\ Associate Professor \\ Kasem Bundit University \\ Thailand \\ suniti.sup@kbu.ac.th
}

\author{
Qudeer Hussain, Thiratha Woracharoensin \\ Lecturer \\ Kasem Bundit University \\ Thailand \\ qudeer.hus@kbu.ac.th, thiratha.w@gmail.com
}

\author{
PANUWAT Joyklad \\ Lecturer \\ Srinakharinwirot University \\ Thailand \\ panuwatj@g.swu.ac.th
}

\begin{abstract}
This study presents results of an experimental investigation conducted to investigate the axial compressive behavior of rope fiber reinforced polymer (RFRP) composite concrete. Natural fiber ropes such as coir, coconut and hemp ropes are easily available both in developing and developed countries. In this study, rope fiber reinforced polymer composite is developed by applying epoxy resin to the natural fiber ropes. The natural hemp rope was applied in three different thicknesses, i.e., one layer, two layers and three layers. Both confined and un-confined concrete columns were tested under monotonic axial compression. The results indicate that rope confinement along with epoxy resin is a very effective method to enhance ultimate strength and strain of confined concrete. The confinement level has a significant effect on the strength and ductility of rope confined concrete. There is found a significant increase in strength and ductility of concrete with an increase in the confinement level.
\end{abstract}

Keywords-Hemp, Rope, Polymer, Composite, Strength and ductility

\section{INTRODUCTION}

Structural members are expected to perform a ductile behavior during earthquakes. The structural members may experience damage due to the inelastic response, but they should survive after earthquakes. Confinement of structural members is a well-known and very effective way to obtain ductile behavior, [1-5]. Many researchers have shown that under axial and lateral loading significant enhancement in terms of strength and ductility can be obtained by confining concrete members with traditional materials such as concrete and steel plates [6, 7]. Concrete jacketing is the addition of a concrete shell surrounding a member that is reinforced to improve the strength and ductility of the concrete elements. Rodriguez and Park (1992) performed seismic load tests on reinforced concrete columns strengthened by concrete jacketing. The as-built columns displayed low available ductility and significant degradation of strength during testing, whereas the jacketed columns behaved in a ductile manner with higher strength and much reduced strength degradation. The retrofit of columns using reinforced concrete jackets was found to be successful, but labor-intensive [8]. The use of externally bonded steel elements such as steel plates, angles and strips has been widely used to strengthen reinforced concrete members [7, 9]. Steel jacketing was found very effective to enhance strength and ductility of strengthened concrete members. The use of steel jacketing does not increase the weight of the structure significantly and saves construction time when compared with reinforced concrete jacket. As an alternative to the traditional jacketing techniques, the use of Fiber Reinforced Polymer (FRP) Composites have been found to be quite effective in the strengthening and repair of existing reinforced concrete structures [10]. These FRP(s) include uni-directional or bi-directional fabrics (such as carbon, glass, aramid, polyethylene terephthalate and polyethylene naphthalates) and sprayed fibers [11, 12]. These FRPs are usually made from synthetic chemicals. The previous studies have shown that FRPs strengthening is very effective to alter the performance of concrete members. Several studies reported skin problems such as irritant and allergic contact dermatitis for workers during synthetic FRP manufacturing and application procedure $[13,14]$. One possible solution to the aforementioned problems would be the replacement of synthetic fibers with natural fibers. Recently, a new method of strengthening RC structures using Natural Fiber Reinforced Polymer composites (NFRP) has been introduced as an alternative to the synthetic FRP composites [15]. Natural fibers such as sisal, hemp, and coconut fibers are made of locally available materials which possess high toughness, low density and suitable strength properties.

Compared to the synthetic FRP, NFRP is cheaper and more environmentally friendly along with a reduced irritation to the skin and respiratory system because they are usually made from plant leaves [15]. However the availability of these natural fibers in the form of fabric sheet is still an issue in many developing countries. In contrast to the natural fiber fabric sheets, a new method of confining concrete by using ropes (coconut, hemp and coir rope) has been developed by researchers $[16,17]$. In this method, dry rope is wrapped around the concrete members using hand layup to confine concrete. This method is cheap and easy to apply compared with existing available strengthening techniques. Shabana et al. 2015 performed an experimental investigation to study the effect of coir rope wrapping on the compressive strength of short axially loaded concrete members. The tests were carried out with ropes of different diameters $0.6 \mathrm{~cm}, 1 \mathrm{~cm}$ and $1.4 \mathrm{~cm}$ at spacing of $0.0 \mathrm{~h}$, $0.1 \mathrm{~h}, 0.2 \mathrm{~h}$ and $0.3 \mathrm{~h}$, where $\mathrm{h}$ is the height of the specimen. Maximum improvement was obtained for wrapping with coir rope of diameter $1.4 \mathrm{~cm}$ at $0.0 \mathrm{~h}$ spacing. The strength was found to be increased with increase in diameter of rope and decreased with increase in spacing [17]. The main objective of the current study is to develop and investigate the efficiency of rope fiber reinforced polymer (RFRP) composite to enhance strength and ductility of concrete. RFRP composite is developed by applying epoxy resin to the natural hemp fiber rope.

The authors are grateful, thankful to the Asian Institute of Technology (AIT), Thailand for providing test facilities to carry out this research. 


\section{EXPERIMENTAL PROGRAM}

\section{A. Specimen Details}

In this experimental program, small scale concrete columns were constructed and tested to investigate the axial response of hemp fiber rope confined concrete. The nominal dimensions of concrete columns are shown in the Fig. 1.
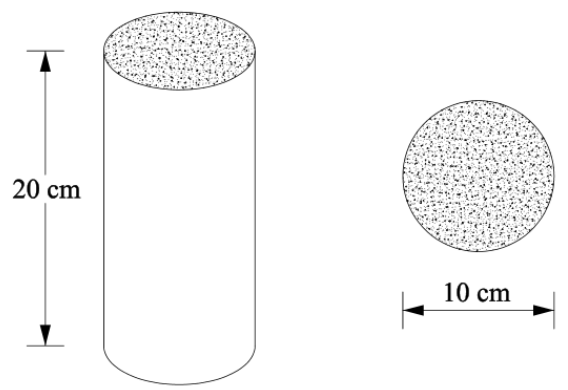

Fig. 1. Details of test specimen.

\section{B. Test Matrix}

A total of eight concrete columns were tested to investigate the axial response of hemp fiber rope confined concrete. Two concrete columns were tested without rope confinement as control specimens and remaining six concrete columns were wrapped with hemp rope. Hemp rope confinement was provided in three layers, i.e., one layer, two layers and three layers. The details of experimental program are summarized in Table I.

TABLE I. DETAILS OF TEST MATRIX

\begin{tabular}{|c|c|c|}
\hline Specimen & Rope layers & No. of specimens \\
\hline CON & - & 2 \\
\hline RE-1 & One & 2 \\
\hline RE-2 & Two & 2 \\
\hline RE-3 & Three & 2 \\
\hline
\end{tabular}

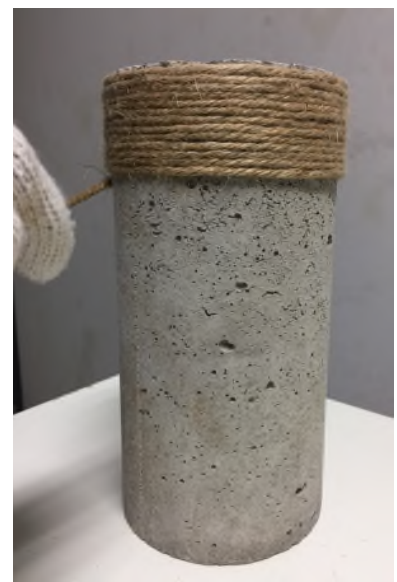

Fig. 2. Wrapping processes of dry rope to the concrete specimen.

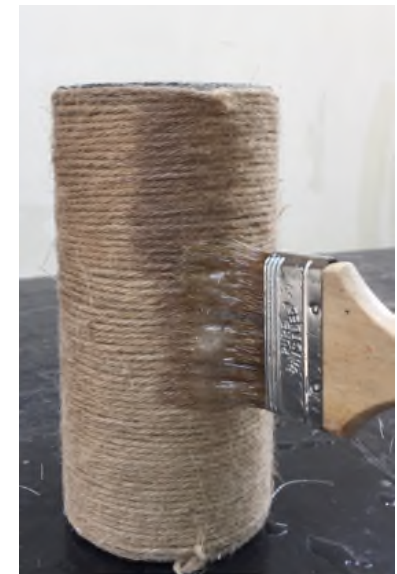

Fig. 3. Applying the epoxy resin using resin

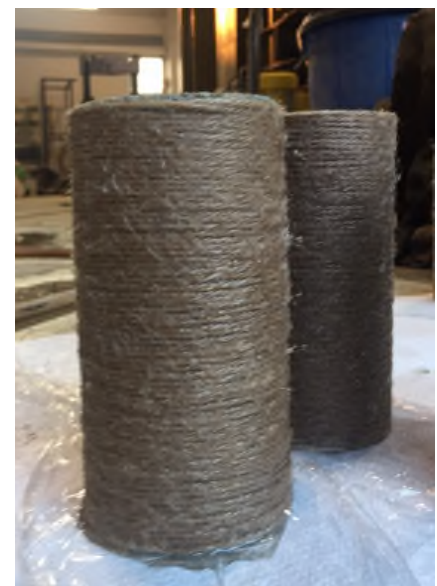

Fig. 4. Typical RFRP strengthened specimen.

\section{RFRP Strengthening Process}

In this study, the RFRP strengthened specimens were developed by applying epoxy resin to the natural hemp fiber rope. In the first step, dry hemp rope (diameter $3 \mathrm{~mm}$ ) was wrapped around the concrete specimens as shown in the Fig. 2. In the second step, the epoxy resin was applied to the surface of hemp fiber ropes to develop rope reinforced polymer (RRP) composite. The natural hemp rope was applied in three different thicknesses, i.e., one layer, two layers and three layers. A typical RFRP strengthened specimen is shown in the Fig. 3 to Fig. 4.

\section{Test Setup}

All concrete columns were tested under uni-axial monotonic axial compression up to failure in a Universal Testing Machine (UTM) of $1000 \mathrm{kN}$ capacity. The load was applied at a constant rate of $0.5 \mathrm{~mm} /$ minute and data were recorded at the time interval of 3 seconds by an electronic data logger. Prior to the testing the column ends were additionally wrapped with glass fiber roving to avoid premature failure of the columns at the ends. A schematic of loading setup is shown in Fig. 5. 


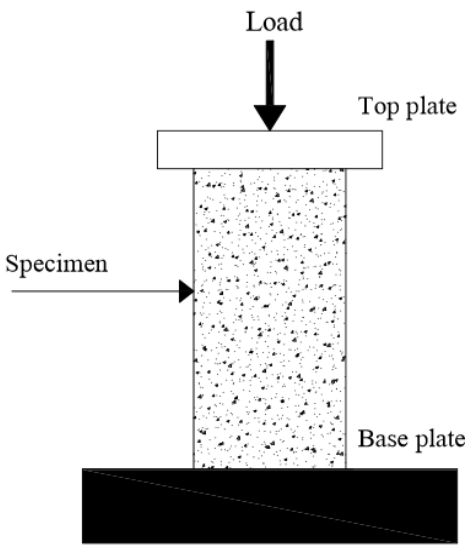

Fig. 5. Typical load setup

\section{E. Material Properties}

In this study, a single batch of concrete (28 day's target strength was $15 \mathrm{MPa}$ ) was used to cost the concrete specimens. Type-1 Portland cement was used to prepare concrete. The nominal size of coarse aggregates was $19 \mathrm{~mm}$. The hemp fiber ropes were obtained from the local supplier. The nominal diameter of hemp fiber rope was $3 \mathrm{~mm}$. The epoxy resin used in this system was provided by Smart and Bright Co., Ltd. Thailand.

\section{TEST REsUlTS AND DISCUSSION}

\section{A. Overall Behavior and Stress-Strain Response}

The axial stress versus strain responses of control and rope confined columns are shown in the Fig. 6. As can be seen that irrespective of confinement level, the typical stress, strain response of hemp rope confined concrete is tri-linear (composed of three parts). The first part of the curve is described by a linear line similar to the curve of the unconfined concrete. Second part is transition part and the third part is linear up to the rupture of RFRP composite.

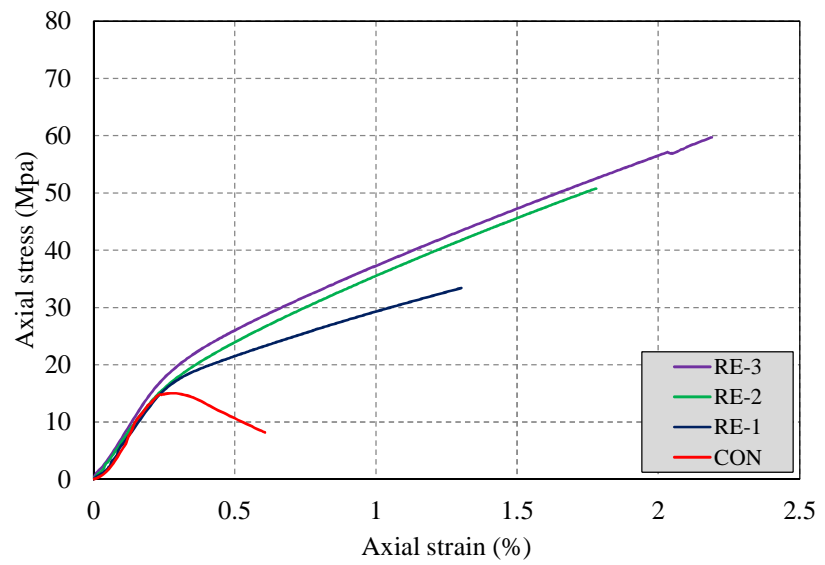

Fig. 6. Stress-Strain response of rope reinforced polymer composites concrete.
TABLE II. EXPERIMENTAL TEST RESULTS.

\begin{tabular}{|c|c|c|c|c|}
\hline Specimen & $\begin{array}{c}\text { Ultimate } \\
\text { stress } \\
\text { (MPa) }\end{array}$ & $\begin{array}{c}\text { \% Increase } \\
\text { in ultimate } \\
\text { stress }\end{array}$ & $\begin{array}{c}\text { Ultimate } \\
\text { strain } \\
(\boldsymbol{\%})\end{array}$ & $\begin{array}{c}\text { \% Increase } \\
\text { in ultimate } \\
\text { strain }\end{array}$ \\
\hline CON & 15.03 & - & 0.21 & - \\
\hline RE-1 & 33.41 & 122.0 & 1.30 & 519.0 \\
\hline RE-2 & 50.77 & 238.0 & 1.78 & 748.0 \\
\hline RE-3 & 59.73 & 297.0 & 2.19 & 943.0 \\
\hline
\end{tabular}

\section{B. Effect of Rope Thickness}

The experimental results indicate that confinement level has a significant effect on the ultimate load carrying capacity and strain of confined concrete. There is found an increase in ultimate load carrying capacity and ultimate strain of hemp rope confined concrete with an increase in the confinement level. The concrete column RE-1 (one layer of hemp rope) failed at $122 \%$ and 519\% higher compressive strength and axial strain, respectively, compared to the control column. When the thickness of the rope was increased to two layers as in the column RE-2, the compressive strength and strain were increased by $238 \%$ and $748 \%$, respectively. The highest increase in compressive strength and strain was $297 \%$ and $943 \%$, respectively, recorded for the column R-3 with three layers of hemp fiber rope. Based on experimental results, it can be concluded that rope strengthening is a very effective technique to enhance both strength and ductility of concrete members. The experimental results also indicate that rope strengthening is an effective solution to replace the existing strengthening techniques such as carbon and glass fiber reinforced polymer composites.

\section{Failure Modes}

The typical failure modes of RFRP strengthened specimens are shown in the Fig. 7 to Fig. 9. The final failure mode of RFRP strengthened specimens was explosive with a large sound. All RFRP strengthened specimens were failed with the rupture of RFRP composite. This type of failure (rupture of FRP composite) has been also observed in the existing literature.

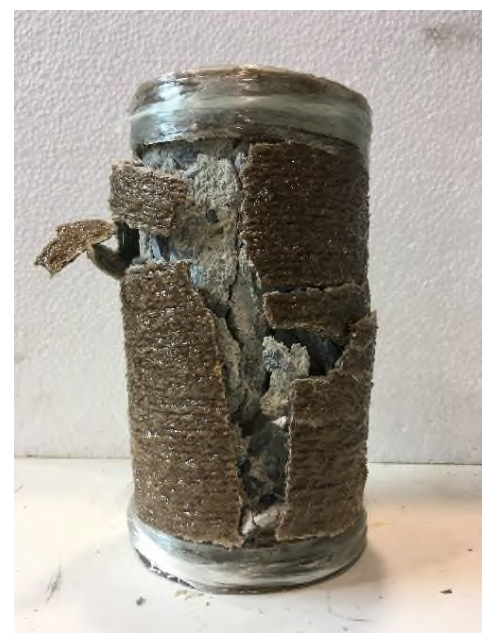

Fig. 7. Typical failure mode of RE-1 specimen. 


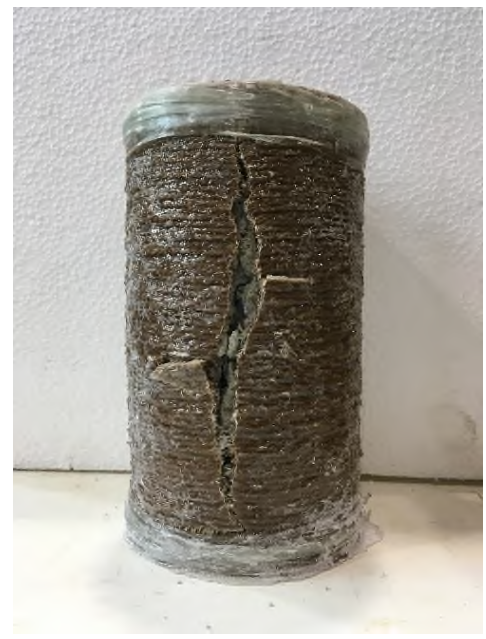

Fig. 8. Typical failure mode of RE-2 specimen.

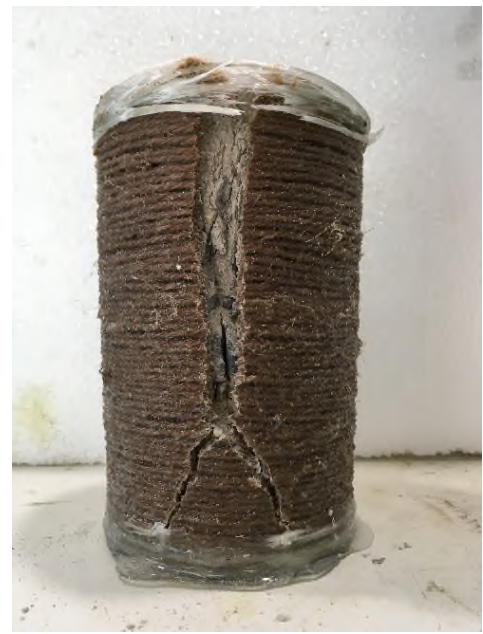

Fig. 9. Typical failure mode of RE-3 specimen.

\section{CONCLUSIONS}

This study presents results of an experimental investigation conducted to investigate the axial compressive behavior of rope confined concrete. In this study, rope fiber reinforced polymer composite is developed by applying epoxy resin to the natural fiber ropes. Based on experimental results following conclusions can be drawn;

1. Natural Rope fiber reinforced polymer composite can be effectively developed by applying epoxy resin to the hemp rope.

2. Confinement to the concrete using rope fiber reinforced polymer composite is an effective method to enhance strength and ductility of concrete.

3. The increase in the compressive strength and ductility varies with the rope thickness.

\section{Acknowledgement}

The authors are grateful, thankful to the Asian Institute of Technology (AIT), Thailand for providing test facilities to carry out this research.

\section{REFERENCES}

[1] D.C. Kent, R. Park. "Flexural members with confined concrete". ASCE J. Struct. Div. vol. 97, no. ST7, pp. 1969-1990, 1971.

[2] J.B. Mander, M.J.N. Priestley, R. Park. "Theoretical stress-strain model for confined concrete". ASCE J. Struct. Div. vol. 114, no. 8, pp. 1804-1826, 1988.

[3] J.B. Mander, M.J.N. Priestley, R. Park. "Observed stress-strain behavior of confined concrete”. ASCE J. Struct. Div. vol. 114, no. 8, pp. 1827-1849, 1998.

[4] M. Saatcioglu, S.R. Ravzi. "Strength and ductility of confined concrete". ASCE J. Struct. Div. vol. 118, no. 6, pp. 1590-1607, 1992.

[5] A. Ilki, P. Ozdemir, T. Fukuta. Confinement effect of reinforced concrete columns with circular cross-section. BRI Research Paper 1997 No. 143, Building Research Institute, Tsukuba, Japan, 1997.

[6] E.N. Júlio, F.A. and Branco, "Reinforced concrete jacketing-interface influence on cyclic loading response". ACI Struct. J. vol. 105, no. 4, pp. 471, 2008.

[7] P.A. Calderón, J.M. Adam, S. Ivorra, F.J. Pallarés, and E. Giménez, "Design strength of axially loaded RC columns strengthened by steel caging". Mater. Des. vol. 30, no. 10, pp. 4069-4080, 2009.

[8] M.L. Rodríguez, and R. Park, Lateral load response of reinforced concrete columns strengthened by jacketing. International Symposium on Earthquake Disaster Prevention, pp. pp. 148-56. México. Centro Nacional de Prevención de Desastes, pp. CENAPRED Japón. Agencia de Cooperación Internacional, pp. JICA NU. Centro para el Desarrollo Regional, pp. UNCRD, 1992.

[9] J.M. Adam, E. Giménez, P.A. Calderón, F.J. Pallarés, and S. Ivorra, "Experimental study of beam-column joints in axially loaded RC columns strengthened by steel angles and strips". Steel Compos. Struct, vol. 8, no. 4, pp. 329-342, 2008.

[10] T.C. Triantafillou, E. Choutopoulou, E. Fotaki, M. Skorda, M. Stathopoulou, and K. Karlos, "FRP confinement of wall-like reinforced concrete columns". Mater. Struct. vol. 49, no. 1-2, pp. 651-664, 2016

[11] M.J. Chajes, T.A. Thomson, T.F. Januszka, and W.W. Finch, "Flexural strengthening of concrete beams using externally bonded composite materials", Constr. Build. Mater. vol. 8, pp. 191-201, 1994.

[12] T. Norris, H. Saadatmanesh, and M.R. Ehsani, "Shear and flexural strengthening of R/C beams with carbon fiber sheets", J. Struct. Eng. vol. 123, pp. 903-911, 1997.

[13] K. Tarvainen, R. Jolanki, L. Forsman-Grönholm, T. Estlander, P. Pfäffli, J. Juntunen, et al., "Exposure, skin protection and occupational skin diseases in the glass fibre reinforced plastics industry", Cont. Dermat. vol. 29, pp. 119-127, 1993.

[14] K. Tarvainen, R. Jolanki, and T. Estlander, "Occupational contact allergy to unsaturated polyester resin cements", Cont. Dermat. vol. 28, pp. 220-224, 1993.

[15] T. Sen and H.J. Reddy, "Efficacy of bio derived jute FRP composite based technique for shear strength retrofitting of reinforced concrete beams and its comparative analysis with carbon and glass FRP shear retrofitting schemes", Sustain. Cities Soc. vol. 13, pp. 105-124, 2014.

[16] T.C. Rousakis, "Hybrid confinement of concrete by fiber-reinforced polymer sheets and fiber ropes under cyclic axial compressive loading”. J. Comp. Constr. vol. 17, no. 5, pp. 732-743, 2013.

[17] S.K. Shabana, M.M. Athira, S.S. Lalna, C. Prasun, K.K. Rafeekha, K.R. Rajimol, and A.M. Safna, Effect of Coir Rope Wrapping on the Compressive Strength of Short Axially Loaded Concrete Members, International Journal of Research in Advent Technology, pp. E-ISSN: 2321-9637 Special Issue International Conference on Technological Advancements in Structures and Construction "TASC- 15", 10-11 June 2015, pp. 20-25. 